\title{
Fungal Decay, Coating, Burning Properties and Change of Color of Particleboards Manufactured with Woody Biomass, Agricultural Wastes and Tetra Pak Residues
}

\author{
Róger Moya $^{1^{*}}$, Diego Camacho ${ }^{1}$, Julio Mata ${ }^{2}$, Roy Soto Fallas ${ }^{3}$ \\ ${ }^{1}$ Escuela de Ingeniería Forestal, Instituto Tecnológico de Costa Rica, Cartago, Costa Rica; ${ }^{2}$ Escuela de Química, Facultad de Ciencias, \\ Universidad de Costa Rica, San José, Costa Rica; ${ }^{3}$ Escuela de Química, Facultad de Ciencias Exactas y Naturales, Universidad \\ Nacional, Heredia, Costa Rica. \\ Email: ${ }^{*}$ rmoya@itcr.ac.cr
}

Received July $11^{\text {th }}, 2013$; revised August $12^{\text {th }}, 2013$; accepted September $1^{\text {st }}, 2013$

Copyright (C) 2013 Róger Moya et al. This is an open access article distributed under the Creative Commons Attribution License, which permits unrestricted use, distribution, and reproduction in any medium, provided the original work is properly cited.

\begin{abstract}
Lignocellulosic residues resulting from agricultural activities and urban centers cause pollution. A possible solution to this problem is to combine these residues with woody plants to produce particleboards. The purpose of this study was to evaluate decay resistance, coating and burning properties and the change of color caused by accelerated weathering of particleboards manufactured with a combination of 3 woody species used for commercial reforestation in tropical areas (Cupressus lusitanica, Gmelina arborea and Tectona grandis), pineapple (Ananas comosus) leaves from the crown and the plant (PL), empty fruit bunch of Elaeis guineensis (EBF) and tetra pak packages (TP). According to the results, the mixtures of $T$. grandis and EFB were classified as moderately resistant and other mixtures (woody species and PL or TP) were classified as slightly resistant. The finish performance test determined that the mixtures with TP presented the best performance, followed by the mixtures with oil palm components and the mixtures composed of pineapple leaves. Regarding lacquer consumption, no differences were found between the mixtures. The combustion test determined that particleboards with TP and EFB showed the highest resistance to combustion, while pineapple presented the lowest resistances to combustion. In the accelerated weathering exposure test, the mixtures of the three species with TP showed the best performance in accelerated weathering. Contrariwise, the mixtures with pineapple leaves showed the lowest resistance to accelerated weathering. Oil palm particleboards presented lower resistance to weathering than TP, though higher than pineapple leaves' resistance.
\end{abstract}

Keywords: Tropical Species; Particleboards; Lignocellulosic Residues; Agricultural Crop

\section{Introduction}

Tropical regions have environmental factors that favor excellent levels of productivity in agricultural crops [1]. It is estimated that 47,000 hectares have been planted with oil palm and 40,000 hectares with pineapple in Costa Rica [2], with the disadvantage that residues from these crops are not being used. Khalil et al. [3] mention that an oil palm plantation produces about 350 ton of residues/ha/rotation, while Araya [4], found that a pineapple plantation produces around 220 ton/ha per rotation. The limited use of these residues is attributed to a lack of technology for their processing and of commercial products that allow their management [5].

On the other hand, tetra pak packages account for

\footnotetext{
"Corresponding author.
}

large quantities of waste material worldwide. According to estimations, around 150 trillion packs were produced in 2010 (www.tetrapak.com), to pack and preserve milk, juice, nectars and others [6]. This product decomposes slowly, thus, high technology such as plasma treatment is required to recycle it [7].

Having said this, it is important to find an adequate way to use agricultural residues and tetra pak packages [8]. One possible alternative is to use them to manufacture already established products, such as particleboards. According to estimations, 81.5 million $\mathrm{m}^{3}$ of particleboards were produced in 2004 and their production continues to grow [9].

Lignocellulosic materials are commonly added to products like particleboards. For example, particleboards 
have been produced using straw and wood from Pinus sylvestris [10], tetra pak packages and Pinus sp. [6]; and bagasse (Saccharum spp) with Eucalyptus grandis [11]. In order to obtain stable and commercially-easy-todevelop particleboards, it is important to consider the interaction between the components of the various types of materials in these mixtures [12]. Good interaction of the materials in the mixture allows obtaining similar mechanical resistance values to those of traditional pure wooden particleboards. Additionally, its water retention and dimension stability are enhanced, and resistance to pathogens such as mold and rot fungi is increased $[13,14]$. Previous manuscript [15] shows that particleboards manufactured with woody species used in this study ( $G$. arborea, $C$. lusitanica and $T$. grandis) combined with tetra pak packages presented the best physical and mechanical properties and particleboards using a mixture of pineapple leaves showed lower values for the properties evaluated.

The objective of this study is therefore to evaluate decay resistance, color change by accelerated weathering exposure, response to application of finishes and combustion properties of particleboards manufactured with combinations of 3 species planted for commercial purposes in tropical areas (Cupressus lusitanica, Gmelina arborea and Tectona grandis), with pineapple leaves from the crown and the plant, fruit and bunch of oil palm and discarded tetra pak packages.

\section{Material and Methods}

\subsection{Raw Materials}

1) Woody biomass corresponded to Gmelina arborea (GA) from a 9 year old plantation, Tectona grandis (TG) from a 16 year old plantation, and Cupressus lusitanica (CL) from a 22 year old plantation (all of them used for commercial reforestation in tropical countries); 2) Agriculture wastes consisted of pineapple leaves (PL) and residues of oil palm from the extraction of oil empty fruit bunch of oil palm (EBF) and oil palm mesocarp fiber of the fruit (OPMF). PL came from an 18 month old plantation and they were used from the crown (PLC) and from the plant (PLP); and 3) Tetra Pak packages residues (TP) were obtained from recycling centers located at Cartago downtown in Costa Rica. Table 1 presents a summary of the raw materials used in the particleboards fabrication.

\subsection{Material Preparation}

Pineapple leaves and oil palm residues were dried following the methodology given by Tenorio and Moya [16]. OPMF residues were washed for one hour in hot water stirring continuously, in order to obtain the best
Table 1. Summary of the blends utilized in the particleboards fabrication.

\begin{tabular}{cccccc}
\hline \multirow{2}{*}{ Species } & \multicolumn{5}{c}{ Types of residues } \\
\cline { 2 - 6 } & $P L C$ & $P L P$ & $E F B$ & OPMF & $T P$ \\
\hline Cupressus & $50: 50$ & $50: 50$ & $50: 50$ & $50: 50$ & $50: 50$ \\
lusitanica & $(6 \%)^{*}$ & $(8 \%)$ & $(8 \%)$ & $(8 \%)$ & $(8 \%)$ \\
Gmelina & $50: 50$ & $50: 50$ & $50: 50$ & $50: 50$ & $50: 50$ \\
arborea & $(8 \%)$ & $(6 \%)$ & $(6 \%)$ & $(8 \%)$ & $(8 \%)$ \\
Tectona & $50: 50$ & $50: 50$ & $50: 50$ & $50: 50$ & $50: 50$ \\
grandis & $(8 \%)$ & $(6 \%)$ & $(8 \%)$ & $(8 \%)$ & $(8 \%)$ \\
\hline
\end{tabular}

*Percentage of urea-formaldehyde adhesive used in the particle-board. PLC: Pineapple leaves from the crown, PLP: Pineapple leaves from the plant, EFB: Empty fruit bunch of oil palm, OPMF: Oil palm mesocarp fiber of the fruit and TP: Tetra Pak package.

performance with adhesives [17]. TP were washed to eliminate residual contents and then they were cut into 1 $\mathrm{cm}$ wide strips, using a paper cutter. The three woody species were chipped to size less than $3 \mathrm{~mm}$. Then a Retsch cutting mill was used to reduce the dried chips into particles that resulted of sizes between 0.7 and 6.0 $\mathrm{mm}$. Finally, the particles of each material were placed into a climate-controlled chamber to obtain $6 \%$ equilibrium moisture content.

\subsection{Particleboard Preparation}

Blends of woody biomass and residues (agricultural and TP packages) used for the particleboard preparation are presented in Table 1. They all were prepared using a 50:50 ratio. The adhesive used was urea-formaldehyde (UF) with $62 \%$ solids, and the adhesive application corresponded to percentages between $6 \%-8 \%$ with respect to the total weight of the particleboard. The amount of adhesive applied was taken from previous research [17]. In total, fifteen different blends were prepared and twenty $35 \times 35 \mathrm{~cm}$ boards were obtained from each mixture. The target particleboard density was of $0.65 \mathrm{~g} / \mathrm{cm}^{3}$, with an average thickness of $12.5 \mathrm{~mm}$ and 3 layers. The two external layers or faces $(2 \mathrm{~mm}$ thick) contained fine particles 0.7 to $1.5 \mathrm{~mm}$ long while the inner layer (core) contained thicker particles 1.5 to 6.0 $\mathrm{mm}$ long. Particleboards were pressed at $25 \mathrm{MPa}$ and $175^{\circ} \mathrm{C}$ for 10 minutes and after that they were put into a climate-controlled chamber during 24 hours to homogenize their moisture content and to finish their adhesive curing process.

\subsection{Fungal Decay Resistance}

Two decay resistant specimens $\left(2.5 \times 2.5 \times 1.2 \mathrm{~cm}^{3}\right)$ were cut from each sheet. The white-rot fungi Trametes versicolor L. Fr. and Gloeophyllum trabeum (Pers.) Murrill, (Brown-rot fungi) were used for testing natural decay resistance following ASTM D-2017 Standard [18]. 
The relative resistance of each test block to decay was measured as the percentage loss in relation to initial weight during a 16-week exposure to the fungi. Although ASTM D-2017 specifies that sample dimensions are 2.5 $\times 2.5 \times 0.9 \mathrm{~cm}$, we modified the procedure to use $2.5 \mathrm{~cm}$ (width) $\times 2.5 \mathrm{~cm}$ (length) $\times 1.2 \mathrm{~cm}$ (thickness) samples. Resistance rating for fungal decay was established according to ASTM Standard D-2017 [18], which classified fungal decay resistance in non-resistant when weight loss is higher than $45 \%$, slightly resistant for weight loss from $25 \%$ to $45 \%$, moderately resistant for 11 to 24 in weight loss and resistant for weight loss from lower than $10 \%[18]$.

\subsection{Accelerated Weathering Exposure and Wood Color Change of Particleboards}

Samples extracted $(5.0 \mathrm{~cm}$ width $\times 15.0 \mathrm{~cm}$ in length and $1.2 \mathrm{~cm}$ in thick) from particleboard sheets were applied an accelerated weathering test, for which a weathering Q-Lab camera was used (QUV/spray model). The ASTM G-152 Standard [19] was applied for this test. The exposure was of five-hour cycles in two phases: firstly, three hours of UV radiation at $60^{\circ} \mathrm{C}$ and a radiation of $0.63 \mathrm{w} / \mathrm{m}^{2}$ (with an UVA mercury bulb and $310 \mathrm{~nm}$ wave length), then a second phase of condensation which took two hours and consisted of using evaporated water at $50^{\circ} \mathrm{C}$ temperature. The total exposure time was 600 hours, except for particleboards with PLC and PLP, because samples supported $350 \mathrm{hrs}$. Color was measured in intervals of 50 hours with a Hunter Lab mini Skan XE Plus spectrophotometer. Color difference $\left(\Delta E^{*}\right)$ was determined as the net color variation for each finish in a period of time according to the ASTM D 2244 Standard [20] whose formula is detailed in Equation (1). The change in color was determined between color before and after accelerated weathering exposure.

$$
\Delta E^{*}=\sqrt{(\Delta L)^{2}+(\Delta a)^{2}+(\Delta b)^{2}}
$$

where: $\Delta E^{*}$ : wood color difference; $\Delta L: L^{*}$ before weathering; $L^{*}$ after 600 hours of weathering; $\Delta a: a^{*}$ before weathering; $a^{*}$ after 600 hours of weathering; $\Delta b$ : $b^{*}$ before weathering; $b^{*}$ after 600 hours of weathering.

\subsection{Coating Performance}

Samples extracted $(5.0 \mathrm{~cm}$ width $\times 15.0 \mathrm{~cm}$ length and $1.2 \mathrm{~cm}$ thickness) from the particleboard sheets were applied lacquer finish (from nitrocellulose resins and nitrated plasticizers). Sealant was previously applied to the samples. The base of this sealant was of concentrated methyl methacrylate, diluted in a 1:3 ratio with thinner. Evaluation took into consideration finish consumption (finish grams $/ \mathrm{m}^{2}$ ) on the surface of the particleboards.
The samples were initially weighed and four layers of nitrocellulose sealant and two layers of nitrocellulose lacquer (composed of nitrocellulose resins and plasticizers) were applied using an ordinary paintbrush. Both the sealant and the lacquer were applied according to recommendations given by the manufacturer. Once the last layer was dry, the sample was weighed and the film thickness (FT) was measured in $\mu \mathrm{m}$ using a Positector (200 series) coating meter, which measures FT following the ASTM D-6123 Standard [21]. Consumption of coating was determined based on the difference between the weight before and after coating application and expressed according to the sample area. Three types of consumption were determined: the first, Sealant Consumption (SEA), which corresponds to the amount of dry sealant left on the particleboard's surface after four applications of this finish; the second type of consumption corresponds to Lacquer Consumption (LAC), applied on two occasions to the surface with sealant; and the third parameter evaluated corresponds to the Total Consumption (TC), that is, the sum of SEA and LAC.

\subsection{Burning Test}

Two samples $(2.0 \mathrm{~cm}$ width $\times 15.0 \mathrm{~cm}$ length and $1.2 \mathrm{~cm}$ thickness) of each of the formulations were evaluated in a high temperature chamber proposed by Castro and Costa [22] to evaluate the combustion properties. In the chamber, the test tubes were placed on a base on a scale in a compartment to reach $500^{\circ} \mathrm{C}$. Weight measurement was performed in periods of one minute until sample combustion was complete. Next, the consumed mass percentage (Equation (2)) and the mass derivative (Equation (3)) on the basis of lapse of time, were estimated. Lastly, these two values were graphed in relation with time.

$$
\begin{array}{r}
M P=\left(\frac{W_{x}}{W_{0 \text { min }}}\right) * 100 \\
\mathrm{~d} m / \mathrm{d} t=\frac{\left(W_{x}-W_{x+1}\right)}{\left(t_{x+1}-t_{x}\right)}
\end{array}
$$

where: $M P$ : Mass Percentage; $W_{x}$ : specific mass at a time of combustion; $W_{0 \min }$ : mass before combustion; $\mathrm{d} m$ : mass derivative; $W_{x+1}$ : a second over of combustion $W_{x} ; t_{x+1}$ : time in $W_{x+1} ; t_{x}$ : it is the time in $W_{x}$.

\subsection{Statistical Analysis}

One-way ANOVA was applied to the results obtained in the decay resistance and finish application tests to find whether there were any significant property differences among the particleboard mixtures of each species. The tests of each of the properties that showed significant 
differences with the ANOVA, were applied the Tukey test with a significance level of $\mathrm{P}<0.05$. The average value of each property was introduced in the model. For all these analyses, the SAS 8.1 statistics program for Windows (SAS Institute Inc., Cary, N.C.) was used. With the results obtained in the accelerated weathering exposure and wood color change test, the values of $\Delta E^{*}$ were compared to the value reported by Cui et al. [23], who determined that if values of $\Delta E^{*}$ equal or higher than twelve are obtained, a total change in color is obtained after a period of weathering exposure.

\section{Results}

\subsection{Fungal Decay Resistance}

Table 2 presents the weight loss percentages (WL) of the particleboards exposed to T. versicolor and G. trabeum. In $\mathrm{CL}$ and $\mathrm{TG}$ particleboards exposed to T. versicolor, the mixtures with oil palm components (EFB and OPMF) showed significantly higher WL values, whereas pineapple leaves mixtures (PLC and PLP) and TP had the lowest significant values of WL. No differences were found for WL values in the mixtures of GA particleboards. With regard to CL particleboards exposed to $G$. trabeum, no differences were found in WL between mixtures with pineapple and oil palm components, while the CL-TP mixture presented the statistically lowest WL value. GA particleboards presented no statistical differences among mixtures of pineapple leaves, OPMF and TP, except for the GA-EFB mixture, being the only one that presented the lowest WL. Finally, TG particleboards presented no differences in the WL values of the five mixtures evaluated (Table 2).

\subsection{Accelerated Weathering Exposure and Wood Color Change of Particleboards}

Variations in $\Delta E^{*}$ are presented in Figure 1, which shows that: 1) $\Delta E^{*}$ increases with time of exposure to UV light in all particleboards; 2) after 350 hours of exposing the mixtures with pineapple components (PLC and PLP) to light, it was not possible to continue with the trial, since UV radiation degraded the external layer of the particleboards; 3) the mixtures of the three species with pineapple components (PLC and PLP) and oil palm components (EFB and OPMF) presented the greatest changes from the beginning of the exposure up to 200 hours; after that period, variations in color were not of the same magnitude; 4) the particleboards manufactured with TP presented the lowest $\Delta E^{*}$ values during the whole period of exposure. Particleboards containing oil palm components (EFB and OPMF) were the least affected, the most affected being therefore those with pineapple leaves components (PLC and PLP).

Table 2. Weight loss of particleboards manufactured of Cupressus lusitanica, Gmelina arborea and Tectona grandis mixed with pineapple leaves, fiber from oil palm fruit and tetra pak package exposed to fungi Trametes versicolor and Gloeophyllum trabeum.

\begin{tabular}{|c|c|c|c|c|c|}
\hline \multirow{2}{*}{ Species } & \multirow{2}{*}{ Treatments } & \multicolumn{2}{|c|}{ Trametes versicolor } & \multicolumn{2}{|c|}{ Gloeophyllum trabeum } \\
\hline & & Weight loss (\%) & Resistance rating ${ }^{*}$ & Weight loss (\%) & Resistance rating \\
\hline \multirow{5}{*}{ Cupressus lusitanica } & PLC & $41.1^{\mathrm{DE}}$ & $\mathrm{Sr}$ & $30.9^{\mathrm{AB}}$ & $\mathrm{Sr}$ \\
\hline & PLP & $39.8^{\mathrm{DE}}$ & $\mathrm{Sr}$ & $32.9^{\mathrm{AB}}$ & $\mathrm{Sr}$ \\
\hline & EFB & $50.2^{\mathrm{ABCD}}$ & $\mathrm{Sr}$ & $30.9^{\mathrm{AB}}$ & $\mathrm{Sr}$ \\
\hline & OPMF & $54.6^{\mathrm{ABCD}}$ & $\mathrm{Sr}$ & $33.7^{\mathrm{A}}$ & $\mathrm{Sr}$ \\
\hline & TP & $36.6^{\mathrm{E}}$ & $\mathrm{Sr}$ & $18.8^{\mathrm{C}}$ & $\mathrm{Sr}$ \\
\hline \multirow{5}{*}{ Gmelina arborea } & PLC & $41.8^{\mathrm{DE}}$ & $\mathrm{Sr}$ & $31.2^{\mathrm{AB}}$ & $\mathrm{Sr}$ \\
\hline & PLP & $42.2^{\mathrm{DE}}$ & $\mathrm{Sr}$ & $27.4^{\mathrm{ABC}}$ & $\mathrm{Sr}$ \\
\hline & EFB & $50.8^{\mathrm{ABCD}}$ & $\mathrm{Sr}$ & $13.6^{\mathrm{C}}$ & $\mathrm{Sr}$ \\
\hline & OPMF & $48.1^{\mathrm{ABCDE}}$ & $\mathrm{Sr}$ & $30.7^{\mathrm{ABC}}$ & $\mathrm{Sr}$ \\
\hline & TP & $54.6^{\mathrm{CDE}}$ & $\mathrm{Sr}$ & $28.2^{\mathrm{AB}}$ & $\mathrm{Sr}$ \\
\hline \multirow{5}{*}{ Tectona grandis } & PLC & $48.3^{\mathrm{ABCD}}$ & $\mathrm{Sr}$ & $27.9^{\mathrm{ABC}}$ & $\mathrm{Sr}$ \\
\hline & PLP & $46.8^{\mathrm{BCDE}}$ & $\mathrm{Sr}$ & $32.1^{\mathrm{ABC}}$ & $\mathrm{Sr}$ \\
\hline & EFB & $59.3^{\mathrm{A}}$ & $\mathrm{Mr}$ & $31.1^{\mathrm{AB}}$ & $\mathrm{Sr}$ \\
\hline & OPMF & $57.7^{\mathrm{A}}$ & $\mathrm{Mr}$ & $31.4^{\mathrm{AB}}$ & $\mathrm{Sr}$ \\
\hline & ТP & $47.5^{\mathrm{BCD}}$ & $\mathrm{Sr}$ & $22.7^{\mathrm{BC}}$ & $\mathrm{Sr}$ \\
\hline
\end{tabular}

*According to ASTM Standard D-2017 (ASTM, 20012c), Sr: Slightly resistant, Mr: Moderately resistant. Averages with equal letters do not present significant differences. Determined at P-value $>0.01$. 


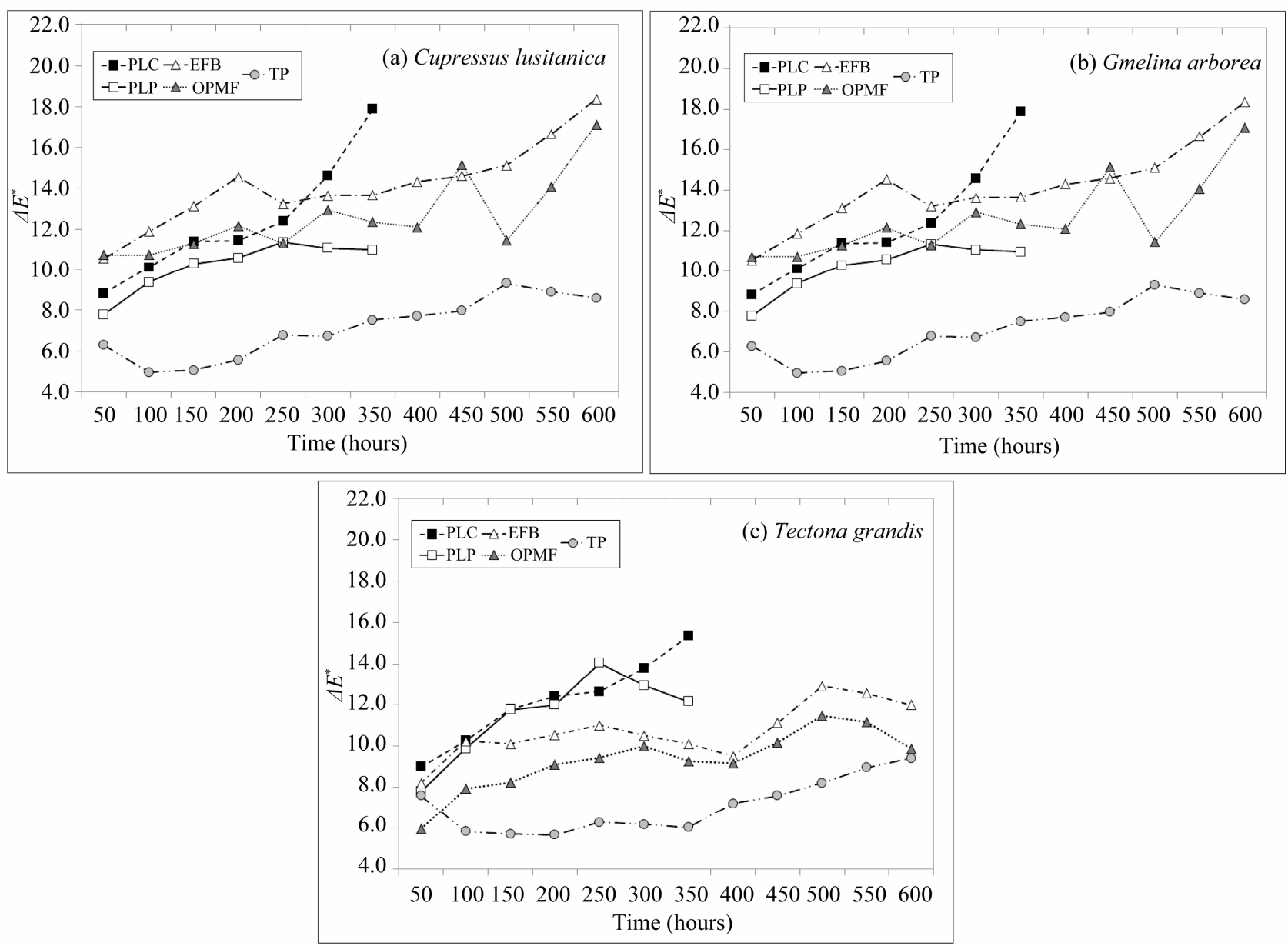

Figure 1. Variation of $\Delta E^{*}$ in relation with time exposed in accelerated weathering exposure test in particleboards manufactured with Cupressus lusitanica, Gmelina arborea and Tectona grandis combined with pineapple leaves, fiber from oil palm fruit and tetra pak package.

\subsection{Coating Performance}

Table 3 shows average SEA, LAC, TC and FT consumption for the particleboards studied. In particleboards with CL and TG, the mixtures with pineapple (PLC and PLP) were found to present the statistically highest values of SEA, while mixtures with TP presented the statistically lowest SEA values.

For GA particleboards, GA-PLP mixture presented the statistically highest values of SEA, while GA-TP mixture had the lowest consumption. Regarding LAC, no statistical differences were found between the five mixtures studied. In relation with TC, particleboards manufactured with CL combined with PLC, and those with a combination of GA and PLP showed significantly higher values compared to the rest of the mixtures. Mixtures containing TP present significantly lower finish consumption. Lastly, in the FT evaluation no significant differences were found among the species and mixtures of lignocellulosic materials studied.

\subsection{Burning Test}

Figure 2 presents the mass percentage (MP) curves and the mass derivative with respect to time for the various kinds of particleboards, where combustion properties appear to be different for each kind of mixture. For CL particleboards (Figure 2(a)), combustion times varied from 25 to 34 minutes; for which CL-TP and CL-EFB mixtures lasted the longest, confirmed by the fact that $-\mathrm{d} m / \mathrm{d} t$ does not present values as high as those of the other particleboards (Figure 2(d)).

Meanwhile, the mixtures with pineapple leaves or OPMF presented the highest values of $-\mathrm{d} m / \mathrm{d} t$ in short periods of time. For GA particleboards (Figure 2(b)) the combustion periods ranged from 24 to 34 minutes. The mixtures with pineapple components (PLC and PLP) and OPMF presented the highest combustion masses during the first minutes (five to eight minutes) (Figure 2(f)), therefore resulting in the highest mass loss (Figure 2(c)). Contrariwise, the mixtures of this species with TP and 
Table 3. Consumption of sealant, lacquer, total and film thickness of particleboards of Cupressus lusitanica, Gmelina arborea and Tectona grandis combined with pineapple leaves, fiber from oil palm fruit and tetra pak package.

\begin{tabular}{|c|c|c|c|c|c|}
\hline Species & Treatment & $\operatorname{SEA}\left(\mathrm{g} / \mathrm{m}^{2}\right)$ & $\operatorname{LAC}\left(\mathrm{g} / \mathrm{m}^{2}\right)$ & $\mathrm{TC}\left(\mathrm{g} / \mathrm{m}^{2}\right)$ & $\mathrm{FT}(\mathrm{mm})$ \\
\hline \multirow{5}{*}{ Cupressus lusitanica } & PLC & $1391^{\mathrm{A}}$ & $403^{\mathrm{A}}$ & $1795^{\mathrm{A}}$ & $2.4^{\mathrm{A}}$ \\
\hline & PLP & $837^{\mathrm{CD}}$ & $363^{\mathrm{A}}$ & $1236^{\mathrm{BCDE}}$ & $1.8^{\mathrm{A}}$ \\
\hline & EFB & $570^{\mathrm{DE}}$ & $338^{\mathrm{A}}$ & $909^{\mathrm{DE}}$ & $2.1^{\mathrm{A}}$ \\
\hline & OPMF & $641^{\mathrm{DE}}$ & $454^{\mathrm{A}}$ & $1098^{\mathrm{CDE}}$ & $2.0^{\mathrm{A}}$ \\
\hline & $\mathrm{TP}$ & $507^{\mathrm{E}}$ & $295^{\mathrm{A}}$ & $802^{\mathrm{E}}$ & $2.2^{\mathrm{A}}$ \\
\hline \multirow{5}{*}{ Gmelina arborea } & PLC & $540^{\mathrm{DE}}$ & $337^{\mathrm{A}}$ & $879^{\mathrm{DE}}$ & $2.0^{\mathrm{A}}$ \\
\hline & PLP & $1300^{\mathrm{AB}}$ & $478^{\mathrm{A}}$ & $1778^{\mathrm{A}}$ & $2.6^{\mathrm{A}}$ \\
\hline & EFB & $668^{\mathrm{DE}}$ & $389^{\mathrm{A}}$ & $1006^{\mathrm{CDE}}$ & $2.0^{\mathrm{A}}$ \\
\hline & OPMF & $705^{\mathrm{DE}}$ & $309^{\mathrm{A}}$ & $1015^{\mathrm{CDE}}$ & $1.5^{\mathrm{A}}$ \\
\hline & $\mathrm{TP}$ & $457^{\mathrm{E}}$ & $335^{\mathrm{A}}$ & $792^{\mathrm{E}}$ & $1.5^{\mathrm{A}}$ \\
\hline \multirow{5}{*}{ Tectona grandis } & PLC & $1272^{\mathrm{AB}}$ & $349^{\mathrm{A}}$ & $1621^{\mathrm{AB}}$ & $2.4^{\mathrm{A}}$ \\
\hline & PLP & $1048^{\mathrm{AB}}$ & $348^{\mathrm{A}}$ & $1395^{\mathrm{ABC}}$ & $2.5^{\mathrm{A}}$ \\
\hline & EFB & $852^{\mathrm{BC}}$ & $372^{\mathrm{A}}$ & $1224^{\mathrm{BCD}}$ & $1.5^{\mathrm{A}}$ \\
\hline & OPMF & $602^{\mathrm{DE}}$ & $364^{\mathrm{A}}$ & $966^{\mathrm{BCDE}}$ & $2.3^{\mathrm{A}}$ \\
\hline & $\mathrm{TP}$ & $407^{\mathrm{E}}$ & $309^{\mathrm{A}}$ & $716^{\mathrm{E}}$ & $2.7^{\mathrm{A}}$ \\
\hline
\end{tabular}

Legend: Averages with equal letters do not present significant differences. Determined at P-value > 0.01. SEA: Consumption of sealant; LAC: Consumption of lacquer; TC: Total consumption and FT: Film thickness.
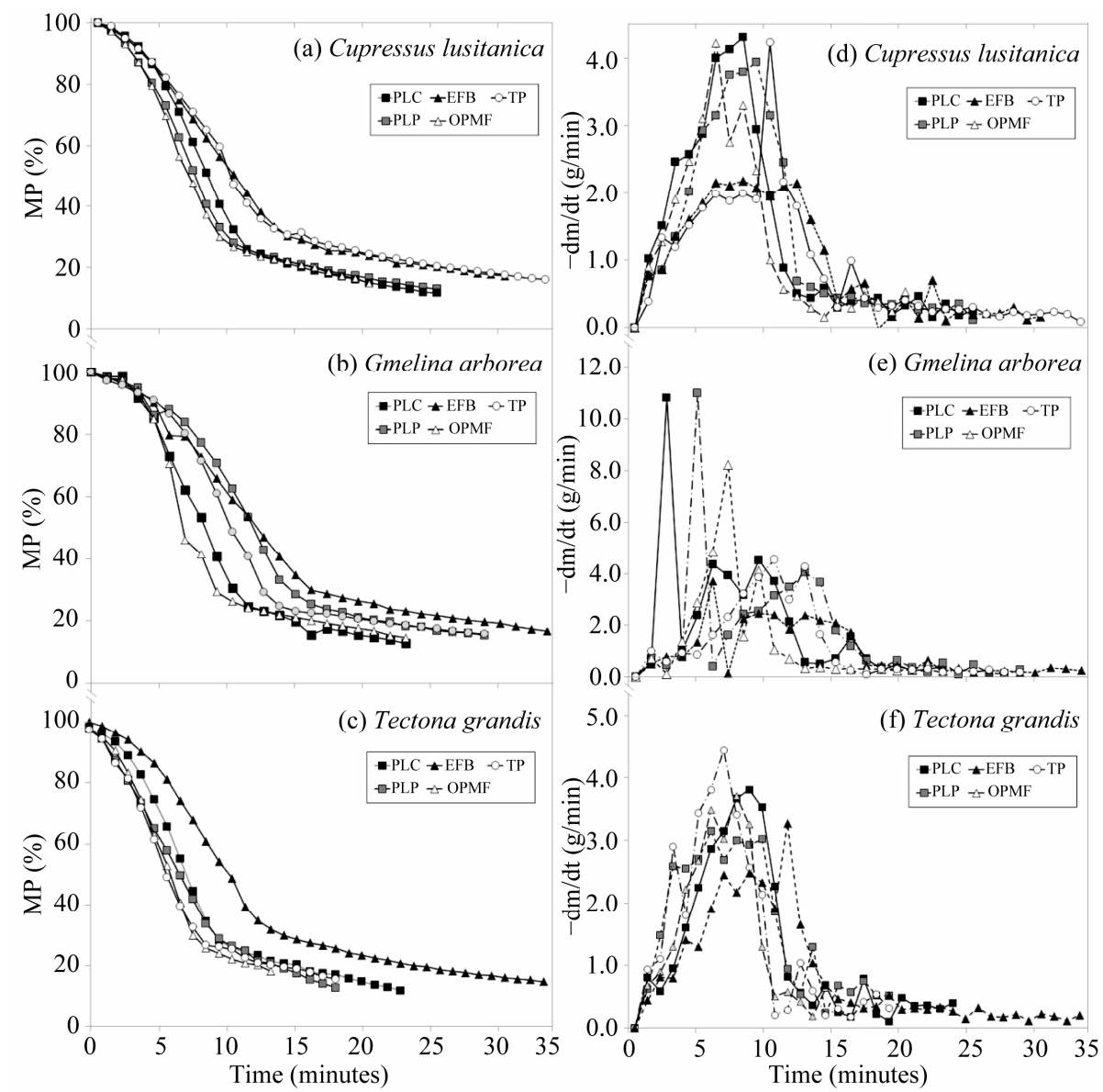

Figure 2. Behavior of MP and the mass of the derivative function of time in particleboards of Cupressus lusitanica, Gmelina arborea and Tectona grandis particleboards combined with pineapple leaves, fiber from oil palm fruit and tetra pak packages during the combustion test. 
EFB presented the lowest mass consumption values in time $(-\mathrm{d} m / \mathrm{d} t)$. Finally, for TG particleboards the combustion periods were from 17 to 34 minutes. The TGEFB mixture was the most significantly resistant to combustion, with the lowest MP (Figure 2(c)) and the lowest $-\mathrm{d} t / \mathrm{d} m$ values (Figure 2(f)). On the other hand, TGOPMF, TG-PLP and TG-TP mixtures showed fast MP reduction, and mass consumption in time occurred at high magnitude (Figure 2(c)) and in short periods of time (Figure 2(f)).

\section{Discussion}

Low WL values with $T$. versicolor in the particleboards manufactured with the mixtures herein studied are similar to values obtained by Walther et al. [14] for particleboards made completely of Hibiscus cannabinus, which had 35\% WL. On the other hand, although statistical analyses show significant differences in the mixtures of each species (Table 2), when categorizing the weight loss values in the resistance categories as established in ASTM D-2017 Standard [18] with $T$. versicolor, all mixtures of CL and GA species are classified as slightly resistant (resistance below 55\%). Regarding particleboards manufactured with TG, TG-EFB and TG-OPMF mixtures were classified as moderately resistant, while the other three GA mixtures were classified as slightly resistant. As regards to G. trabeum, all mixtures of the three species were classified as slightly resistant, since none of them exceeded the maximum value of $55 \%$ needed to surpass the category.

Although all particleboards were classified from slightly to moderately resistant, their resistance may be increased by adding a preservative at the time of manufacturing. For example, Tsunoda [24] demonstrated that using preservatives like boric acid completely reduces the attack of $T$. versicolor and G. trabeum in particleboards of Cryptomeria japónica. Therefore, pathogen inhibitors are recommended to increase the life span of particleboards [25].

Color changes $\left(\Delta E^{*}\right)$ due to time of exposure to UV radiation (Figure 1), are caused by photodegradation processes [26,27], produced by long periods of exposure to UV light. At the beginning of the exposure, photodegradation affects the cell walls of the wood particle in the board, thus generating depolymerization of lignin (mainly because it absorbs $85 \%$ to $90 \%$ of UV light) and cellulose, which both produce changes in color as well as particleboard surface disintegration processes. Lignin depolymerization also generates macroscopic cracks on the particleboard surface [28], which probably affected the performance of pineapple (PLC and PLP) particleboards, enduring only 350 hours of exposure. On the other hand, TP particleboards presented the lowest $\Delta E^{*}$ values, probably due to the high amount of polyethylene and aluminum present, which are more stable than cellulose [26]. Also, TP aluminum can reflect UV light, reducing its effect on the particleboard.

Cui et al. [23] determine that when $\Delta E^{*}$ presents values above twelve, a total change in color is obtained. Considering this parameter and the results obtained, only TP mixtures did not exceed twelve in $\Delta E^{*}$, during the 600 hour exposure, hence achieving the best response to accelerated weathering. A different result was obtained for pineapple (PLC and PLP) and oil palm (EFB and OPMF) mixtures: both groups of mixtures had total color changes $\Delta E^{*}$ exceeding twelve.

Furthermore, particleboards manufactured with TP and the three species presented the lowest finish consumption, because their surfaces are the most homogeneous, with less rugosity than particleboards manufactured with pineapple leaves or oil palm fruit parts [15]. Low rugosity surfaces (homogeneous surfaces) are easier to coat and consume less finish $[29,30]$. Sealant application on the particleboard surface results in homogeneous surfaces (covering empty spaces, defects or irregularities), and allows a homogeneous lacquer coating and consumption by the various kinds of particleboards. Moreover, uniformity of the FT parameter [15] shows how uniform the two kinds of finishes were.

Combustion results (Figure 2) showed that particleboards with lignocellulosic materials from EFB and TP (except for the TG-TP mixture) presented higher combustion resistance, while particleboards of the three species with pineapple residues and OPMF (in addition to the TG-TP mixture) presented the lowest combustion resistance. The latter particleboards present less thermal stability in the presence of flame, therefore increased risk of combustion than particleboards of the first group (particleboards manufactured with EFB and TP).

TP-composed particleboards resist combustion better due to the presence of aluminum and polyethylene in their composition. Korkmaz et al. [7] mention that polyethylene requires over $180^{\circ} \mathrm{C}$ for its total combustion, and aluminum acts as heat reflector, which delays the process. Pineapple leaves particleboards, instead, were easier to burn. $\mathrm{Xu}$ et al. [31] mention that as chemical variability increases in the particleboard mixture, instability of the composition also increases, thus facilitating combustion. This is because chemical variability augments the presence of volatile substances; moreover, flammable waxes and tannins that are present in the particleboard react at temperatures higher than $105^{\circ} \mathrm{C}$ in combustion processes [32]. By means of chemical analysis and grouping tests, previous studies [5] demonstrated that pineapple lignocellulosic residues (PLC and PLP) differ significantly from oil palm residues (EFB and 
OPMF) and from the three woody species, resulting in diverse mixtures and increasing the presence of volatile substances and mixture instability. Regarding oil palm, close relationship with chemical composition of the three species was found, therefore more stable mixtures are obtained [15]. Variations between OPMF and EFB were possibly due to the previous treatment given to OPMF.

\section{Conclusions}

TG-EFB and TG-OPMF mixtures were classified as moderately resistant, while the rest of the mixtures as slightly resistant to $T$. versicolor. In addition, with $G$. trabeum all particleboards of the three woody species were classified as slightly resistant.

In the accelerated weathering exposure test, all mixtures intensified their change of color $\left(\Delta E^{*}\right)$ the longer they were exposed to UV light. However, the mixtures of the three species with TP showed the best performance in accelerated weathering, since $\Delta E^{*}$ did not exceed twelve, which is the value indicating total change in the color of the surface. Contrariwise, the mixtures with pineapple leaves showed the lowest resistance to accelerated weathering, the surface of the particleboard starting to disintegrate after 350 hours of exposure. Oil palm particleboards, on the other hand, presented lower resistance to weathering than TP, though higher than pineapple leaves' resistance.

The finish performance test determined that the mixtures with TP (of all three species) presented the best performance, since the surface showed few irregularities, followed by the mixtures with oil palm components and finally by the mixtures composed of pineapple leaves. Regarding lacquer consumption, no differences were found between the mixtures of the three species, which was attributed to the fact that the sealant homogenized the surface.

Finally, the combustion test determined that particleboards with TP and EFB showed the highest resistance to combustion, while pineapple and OPMF mixtures presented the lowest resistances to combustion. Such behavior is attributed to TP polyethylene and aluminum delaying combustion. Pineapple particleboards, on the other hand, presented the highest combustion capacity due to the heterogeneity of the mixtures, with higher content of extractives and volatile substances. Oil palm particleboards showed higher homogeneity. OPMF and EFM were attributed to a previous treatment applied to OPMF.

\section{Acknowledgements}

We thank the Vicerrectoría de Investigación y Extensión of Instituto Tecnológico de Costa Rica and CONARE for
Financial support. PINDECO and COOPEAGROPAL for providing the raw materials and facilities for this study.

\section{REFERENCES}

[1] F. Bertsch, "El Recurso de la Tierra en Costa Rica," Agronomía Costarricense, Vol. 30, No. 1, 2005, pp. 133155.

[2] GFA Consulting Group, "Informe Final: Estudio del Estado de la Producción Sostenible y Propuesta de Mecanismos Permanentes de Fomento de la Producción Sostenible," Consulting Group, Costa Rica, 2010.

[3] A. H. P. S. Khalil, H. Ismail, M. N. Ahmad, A. Ariffin and K. Hassan, "The Effect of Various Anhydride Modification on Mechanical and Water Absorption Properties of Oil Palm Empty Fruit Bunches Reinforced Polyester Composites," Polymer International, Vol. 50, No. 4, 2001, pp. 1-9.

[4] R. Araya, "Utilización del Rastrojo de Piña (Ananas comusus) Para la Obtención de Pulpa Para la Producción de Papel," Universidad de Costa Rica, Costa Rica, 2010.

[5] R. Moya, D. Camacho, R. Soto Fallas, J. Mata and J. Vega-Baudrit, "Chemical and Extractives Compatibility of Empty Bunch Fruit of Elaeis guineensis, Leaves of Ananas comosus and Tetra Pak Package with Wood Used in Particleboards in Tropical Areas," Latin American Research Apply, 2013, submitted.

[6] M. Hidalgo, "Manufacturing Rigid Board by Packaging Waste Containing Aluminium and Polyethylene," Journal Science Industrial Research, Vol. 70, No. 3, 2011, pp. 232-234.

[7] A. Korkmaz, J. Yanik, M. Brebu and C. Vasile, "Pyrolysis of the Tetra Pak," Waste Management, Vol. 29, No. 11, 2009 , pp. 2835-2841.

http://dx.doi.org/10.1016/j.wasman.2009.07.008

[8] J. B. Ulloa, J. H. Weerd, E. A. Huisman and J. A. J. Verreth, "Tropical Agricultural Residues and Their Potential Uses in Fish Feeds: The Costa Rica Situation," Waste Management, Vol. 24, No. 1, 2004, pp. 87-97. http://dx.doi.org/10.1016/j.wasman.2003.09.003

[9] C. Chapman, "Wood-Based Panels: Particleboard, Particleboard and Oriental Strand Board," In: C. R. Walker, Ed., Primary Wood Process, Springer Verlag, New York, 2006, pp. 427-475. http://dx.doi.org/10.1007/1-4020-4393-7_12

[10] A. H. Grigoriou, "Straw-Wood Composites Bonded with Various Adhesive Systems," Wood Science Technology, Vol. 34, No. 4, 2000, pp. 355-365. http://dx.doi.org/10.1007/s002260000055

[11] U. L. Belini, M. T. Filho, J. L. Penetra, C. Louzada, J. C. Carvalho Rodrigues and J. R. Sartori Astolphi, "Pilot Study for MDF Manufacture from Sugarcane Bagasse and Eucalyptus Fibers," European Journal of Wood Products, Vol. 70, No. 4, 2012, pp. 537-539.

[12] N. Reddy and Y. Yang, "Biofibers from Agriculture 1 Byproducts for Industrial Applications," Trends in Bio- 
technology, Vol. 23, No. 1, 2005, pp. 22-27. http://dx.doi.org/10.1016/j.tibtech.2004.11.002

[13] N. Ayrilmis, "Effect of Panel Density on Dimensional Stability of Medium and High Density Particleboards," Journal of Material Science, Vol. 42, No. 20, 2007, pp. 8551-8557. http://dx.doi.org/10.1007/s10853-007-1782-8

[14] T. Walther, S. N. Kartal, W. J. Hwang, K. Umemura and S. Kawai, "Strength, Decay and Termite Resistance of Oriented Kenaf Fiberboards," Journal of Wood Science, Vol. 53, No. 6, 2007, pp. 481-486. http://dx.doi.org/10.1007/s10086-007-0902-z

[15] R. Moya, D. Camacho, G. Oporto, R. Soto Fallas and J. Mata, "Physical, Mechanical and Other Properties of Particleboards Manufactured with Cupressus lusitanica, Gmelina arborea and Tectona grandis Mixed with Empty Bunch Fruit of Elaeis guineensis, Leaves of Ananas cumosos and Tetra Pack Package," Waste Management and Research, 2013, submitted.

[16] C. Tenorio and R. Moya, "Evaluation of Different Methods Proposal for the Drying of Lignocelluloses Residues," BioResources, Vol. 7, No. 3, 2012, pp. 3500-3514.

[17] R. Moya, D. Camacho, R. Soto Fallas and J. Mata, "Evaluation of Internal Bond Strength of Particleboards Made of Gmelina arborea, Tectona grandis or Cupressus lusitanica Mixture with Empty Fruit Bunch of Elaeis guineensis, Leaves of Ananas comosus or Tetra Pak Packages," Journal of Wood Science, 2013, submitted.

[18] ASTM, "Standard Test Method of Accelerated Laboratory Test of Natural Decay Resistance of Woods," D2017, Philadelphia, 2012.

[19] ASTM, "Standard Practice for Operating Fluorescent Light Apparatus for UV Exposure of Nonmetallic Material," G152, Philadelphia, 2012.

[20] ASTM, "Standard Practice for Calculation of Color Tolerances and Color Differences from Instrumentally Measured Color Coordinates," D2244, Philadelphia, 2012.

[21] ASTM, "Standard Specification for Pressure-Sensitive Tape for Light-Duty Packaging and General Purpose Masking," D-6123, Philadelphia, 2012.

[22] A. Castro and F. S. Costa, "Drying and Burning Characteristics of Ipê Branco Wood Cylinders," Engenheria Térmica, Vol. 6, No. 1, 2007, pp. 35-40.

[23] W. Cui, P. Kamdem and T. Rypstra, "Diffuse Reflectance Infrared Fourier Transform Spectroscopy (DRIFT) and Color Changes of Artificial Weathered Wood," Wood Fiber Science, Vol. 36, No. 3, 2004, pp. 291-301.
[24] K. Tsunoda "Preservative Properties of Vapor-BoronTreated Wood and Wood-Based Composites," Journal of Wood Science, Vol. 47, No. 2, 2001, pp. 149-153. http://dx.doi.org/10.1007/BF00780565

[25] J. Xu, R. Widyorini, H. Yamauchi and S. Kawai, "Development of Binderless Particleboard from Kenaf Core," Journal of Wood Science, Vol. 52, No. 3, 2003, pp. 236243. http://dx.doi.org/10.1007/s10086-005-0770-3

[26] B. George, E. Suttel, A. Merlin and X. Deglise, "Photodegradation ond Photostabilitation of Wood-The State of Art," Polymer Degradation and Stability, Vol. 88, No. 2, 2005, pp. 268-274.

http://dx.doi.org/10.1016/j.polymdegradstab.2004.10.018

[27] M. Deka, M. Humar, G. B. Kricej and M. Petric, "Effects of UV Light Irradiation on Colour Stability of Thermally Modified, Copper Ethanolamine Treated and Non-Modified Wood: EPR and DRIFT Spectroscopic Studies," Wood Science and Technology, Vol. 42, No. 1, 2008, pp. 5-20. http://dx.doi.org/10.1007/s00226-007-0147-4

[28] P. D. Evans, K. Urban and J. A. Chowdhury, "Surface Checking of Wood Is Increased by Photodegradation Caused by Ultraviolet and Visible Light," Wood Science and Technology, Vol. 42, No. 3, 2008, pp. 251-265. http://dx.doi.org/10.1007/s00226-007-0175-0

[29] R. S. Williams and W. C. Feist, "Duration of Wood Preweathering: Effect on the Service Life of Subsequently Applied Paint," Journal of Coatings Technology, Vol. 73, No. 920, 2001, pp. 65-72.

http://dx.doi.org/10.1007/BF02698377

[30] J. P. Davim and C. S. Silva, "Surface Roughness Aspects in Milling MDF (Medium Density Fiberboard)," The International Journal of Advanced Manufacturing Technology, Vol. 40, No. 1, 2009, pp. 49-55. http://dx.doi.org/10.1007/s00170-007-1318-z

[31] Q. Xu, G. L. Griffin, Y. Jiang, C. Preston, A. D. Bicknell, G. P. Bradbury and N. White, "Study of Burning Behavior of Small Scale Wood Crib with Cone Calorimeter," Journal of Thermal Analysis and Calorimetry, Vol. 91, No. 3, 2008, pp. 787-790. http://dx.doi.org/10.1007/s10973-007-8338-7

[32] H. Qu, W. Wu, Y. Jiao, J. Xie and J. Xu, "Investigation on the Thermal Decomposition and Flame Retardancy of Wood Treated with a Series of Molybdates by TG-MS," Journal of Thermal Analysis and Calorimetry, Vol. 105, No. 1, 2011, pp. 269-277.

TP: tetra pack packages

GA: wood of Gmelina arborea

TG: wood of Tectona grandis

CL: wood of Cupressus lusitanica

UF: adhesive of urea-formaldehyde

PLP: pineapple leaves from the plant

EFB: empty fruit bunch of oil palm

OPMF: oil palm mesocarp fiber of the fruit 